\title{
Existing data sources for clinical epidemiology: The Western Denmark Heart Registry
}

This article was published in the following Dove Press journal:

Clinical Epidemiology

19 May 2010

Number of times this article has been viewed

\author{
Morten Schmidt ${ }^{1}$ \\ Michael Maeng ${ }^{2}$ \\ Carl-Johan Jakobsen ${ }^{3}$ \\ Morten Madsen' \\ Leif Thuesen ${ }^{2}$ \\ Per Hostrup Nielsen ${ }^{4}$ \\ Hans Erik Bøtker ${ }^{2}$ \\ Henrik Toft Sørensen' \\ 'Department of Clinical Epidemiology, \\ 2Department of Cardiology, \\ ${ }^{3}$ Department of Anesthesia and \\ Intensive Care, ${ }^{4}$ Department of \\ Cardiothoracic Surgery, Aarhus \\ University Hospital-Skejby, Denmark
}

Correspondence: Morten Schmidt

Department of Clinical Epidemiology,

Aarhus University Hospital, Olof Palmes

Allé 43-45, DK-8200, Aarhus N, Denmark

Tel +4589424800

Fax +4589424801

Email morten.schmidt@dce.au.dk
Background: The Western Denmark Heart Registry (WDHR) has not previously been described as a research tool in clinical epidemiology.

Objectives: We examined the setting, organization, content, data quality, and research potential of the WDHR.

Method: We collected information from members of the WDHR organization, including the committee of representatives, the board, the data management group, and physicians reporting to the database. We retrieved 2008 data from the WDHR to illustrate database variables.

Results: The WDHR is a clinical database within a population-based health care system. It was launched on 1 January 1999 to monitor and improve the quality of cardiac intervention in Western Denmark (population: 3.3 million) and to allow for clinical and health-service research. More than 200,000 interventions, with 50-150 variables each, have been registered. The data quality is ensured by automatic validation rules at data entry combined with systematic validation procedures and random spot-checks after entry.

Conclusions: The WDHR is a valuable research tool because it provides ongoing longitudinal registration of detailed patient and procedural data. The Danish national health care system enables this research because it allows complete follow-up for medical events after cardiac intervention by linkage with multiple medical databases.

Keywords: cardiac surgical procedures, catheterization, coronary angiography, database, epidemiology, registries

\section{Introduction}

The Western Denmark Heart Registry (WDHR) is a clinical database within a population-based health care system. To improve cardiac treatment quality, the Danish National Board of Health decided in 1993 to increase the number of invasive cardiac interventions in Denmark. ${ }^{1}$ In response to this initiative, the WDHR was founded on January 1, 1999 as a collaborative effort by Western Denmark's three major cardiac centers (Aarhus University Hospital-Skejby, Odense University Hospital, and Aarhus University Hospital-Aalborg) in order to monitor the cardiovascular treatment quality in Western Denmark. The remaining cardiac centers in Western Denmark (Varde Heart Centre, Region Hospital Viborg, Region Hospital Herning, Region Hospital Silkeborg, Vejle Hospital, Haderslev Hospital, Aarhus Hospital, Svendborg Hospital, and Hospital of Southwest Denmark-Esbjerg) joined the registry later. The participating centers own the WDHR and finance its operation through annual membership fees set according to hospital size. 
The WDHR serves as a regional data source to the Danish Heart Registry, which also contains data from Eastern Denmark and thus is responsible for the national monitoring of cardiac intervention quality. ${ }^{2,3}$ The WDHR, however, contains several data beyond what is delivered to the Danish Heart Registry. ${ }^{2,3}$ Thus, in addition to monitoring and improving the cardiac intervention quality in Western Denmark, the aim of collecting data to the WDHR is to allow for clinical and health-service research on the use of and outcomes from these procedures. In this study we examined the setting, organization, content, data quality, and research potential of the WDHR.

\section{Setting}

Western Denmark has a population of 3.3 million (55\% of the total Danish population; Figure 1). Denmark provides an optimal environment for conducting medical database-based research because: (i) the Danish National Health Service provides tax-supported universal health care, guaranteeing unfettered access to general practitioners and hospitals, and partial reimbursement for prescribed medications; (ii) cardiac intervention in Western Denmark are performed only at participating cardiac centers; (iii) all Danish citizens can be tracked in the health care system and national registries using the unique ten digit central personal registry (CPR) number assigned to each Danish citizen at birth and to residents upon immigration; ${ }^{4}$ and (iv) information on exposures, disease outcomes, and potential confounding factors can be ascertained through CPR linkage to other Danish medical databases (Figure 2), which store information on eg, citizen vital statistics since 1968, including date of birth, change of address, date of emigration, and exact date of death (The Civil Registration System), ${ }^{5}$ specific causes of death since 1943 (The Registry of Causes of Deaths), ${ }^{6}$ characteristics of all nonpsychiatric inpatient admissions since 1977 and all outpatient clinic visits since 1995 (The National Patient Registry), ${ }^{7}$ prescribed medication since 1995 (The Nationwide Prescription Database), ${ }^{8}$ and all laboratory results from patient blood samples since 1997 (The Laboratory Database). ${ }^{9}$

\section{Organization}

The organization behind the WDHR comprises a committee of representatives, a board, and a data management group. The committee of representatives consists of medical specialists from the cardiac centers and includes nine cardiologists, three cardiac surgeons, and three anesthesiologists. One member from each specialty group is selected for the representatives' executive committee with voting rights on the board. The committee of representatives coordinates all database changes, participates in securing data quality, reports to the Danish Heart Registry, and promotes future initiatives within the WDHR.

In addition to the representatives' executive committee, the board consists of one hospital management representative from each of the three major cardiac centers, among whom the chairman is chosen. The board provides oversight, maintains contracts with database suppliers, sets annual membership fees, defines the strategy and goals for the WDHR, and holds the responsibility for the budget and the data quality to the Danish Heart Registry.

The board appoints a data management group, which holds the responsibility for day-to-day management including implementing database changes, preparing annual reports, and daily communication between the committee of representatives, the board, and the database suppliers.

\section{Study population}

The WDHR includes all adult ( $\geq 15$ years) patients in Western Denmark referred for cardiac intervention, ie, invasive procedures (coronary angiography [CAG] or percutaneous coronary intervention [PCI]), cardiac surgery (predominantly valve surgery and coronary artery bypass grafting $[\mathrm{CABG}]$ ), and from 2008 also computed tomography $(\mathrm{CT}) \mathrm{CAG}$.

Invasive $\mathrm{CAG}$ is performed at all cardiac centers like CT CAG, except at the Region Hospital Silkeborg, Aarhus Hospital, and Svendborg Hospital. PCI and cardiac surgery are performed only at the three major cardiac centers and the Varde Heart Centre. During 2008 more than 23,000 procedures were performed. ${ }^{10}$ By January 2010, the WDHR contained patient data on approximately 120,000 CAGs, 52,000 PCIs, 26,000 cardiac operations including 17,000 CABGs, and 3,000 CT CAGs. ${ }^{10}$

\section{Variables}

The WDHR is derived from an internet-based online system, running on an encrypted public net. The board specifies the data profile. A common interface form secures standardized data collection from the cardiac centers. Data are entered by the physicians into a computer-based data management system using the CPR numbers. Serial numbers for patients and procedures are automatically generated to protect patient confidentiality. There are no paper forms. An integrated help function helps to solve data registration problems. The concept of "one procedure - one interface" provides physicians with a visual overview of the variables to be filled in. Thus, for each procedure, physicians report 

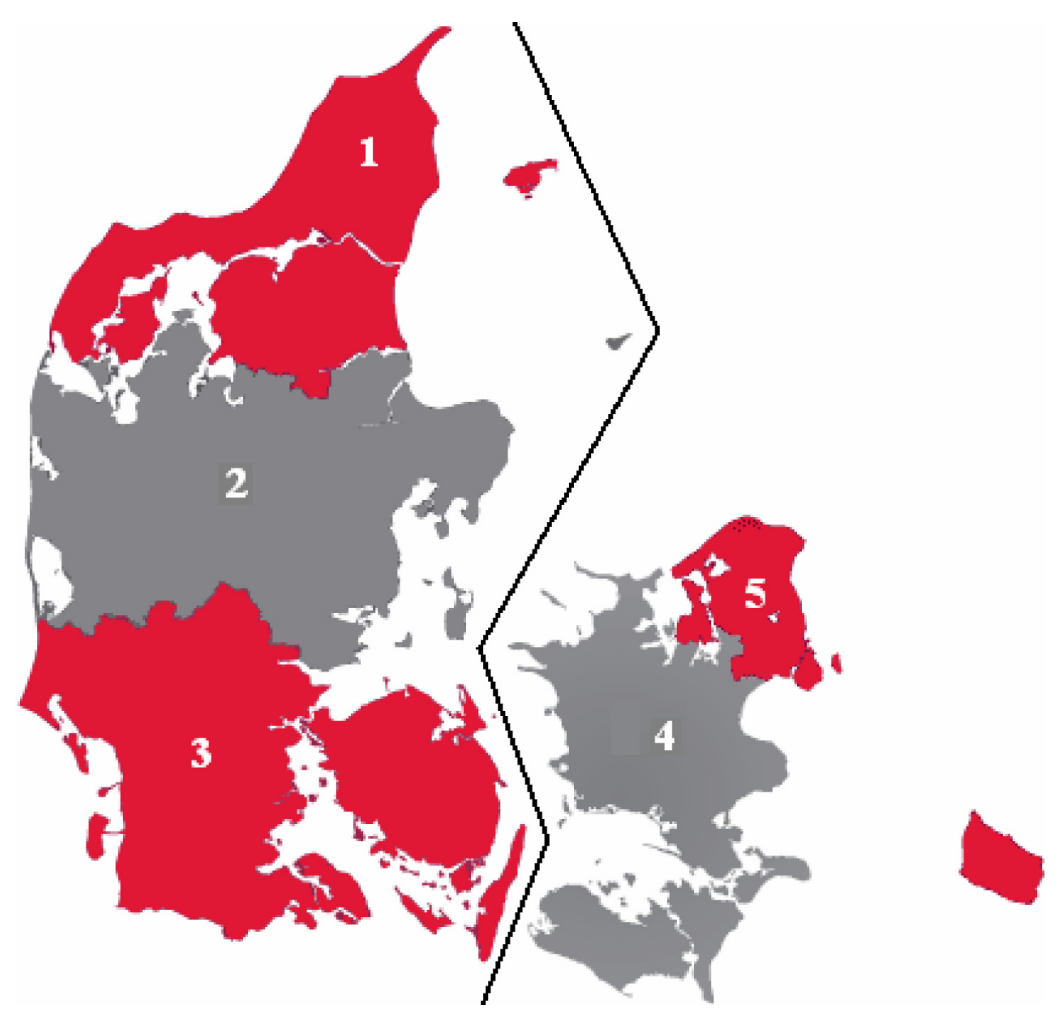

Figure I Western Denmark area. Western Denmark area includes (I) North Denmark Region, (2) Central Denmark Region, and (3) Region of Southern Denmark. Eastern Denmark area includes (4) Sealand Region and (5) Capital Region of Denmark.

administrative data, including dates of referral, admission, operation, and discharge; and clinical data, including medical history, procedure data, lesion data, complications, and research study enrollments (Tables 1-3). Depending on the procedure type, 50 to 150 variables are registered for each procedure.

\section{Treatment quality}

Quantifiable variables have been selected as performance indicators for the quality of the health care efforts compared with prespecified standards set by the Danish Heart Registry (Table 3). ${ }^{11,12}$ The purpose of the performance indicators is to: assess the actual care given and its quality in order to detect care and service processes needing improvement (process indicators, [PI]); assess whether treatment outcomes meet a desired level (outcome indicators, [OI]); maintain and improve quality of care; and inform policy making or strategy at a regional and national level. ${ }^{12}$ The WDHR performance indicators are selected independently for the following interventions: $\mathrm{CAG}$ : adverse reaction to contrast fluid (OI, standard $<1 \%$ ), arrhythmia during procedure (OI, standard $<1 \%$ ), and bleeding complications from arterial puncture (OI, standard $<3 \%$ ); PCI, in addition: acute $\mathrm{CABG}$ during procedure $(\mathrm{OI}$, standard $<0.5 \%$ ), 30-day mortality (OI, standard $<5 \%$ ), and postintervention secondary prophylaxis with clopidogrel and statins (PI, standard $\geq 95 \%$ ); and cardiac surgery: 30-day mortality (OI, standard $<5 \%$ ), central nervous lesion or acute myocardial infarction during hospitalization (OIs, standard $<5 \%$ ), sternum infection (OI, standard $<3 \%$ ), reintervention due to bleeding or within 6 months (OIs, standard $<10 \%$ ), transfusion (PI, standard yet to be defined), and postintervention secondary prophylaxis with statins (PI, standard $\geq 95 \%$ ). Furthermore, improvements in the quality of care are also ascertained through ways other than performance indicators. As an example, the scope of surgery among patients aged 80-90 years has been expanded to include complex surgery with both valve replacement and CABG. This expansion has been justified through surveillance of outcome data by means of the WDHR.

\section{Data quality}

Upgrades to the database platform have been performed in 2003 and 2006. The next upgrade is scheduled for 2010. To improve data quality, it is mandatory to fill in more than two-thirds of the variables. The data quality is confirmed by automatic validation rules at data entry (eg, blood pressure levels are restricted within prespecified limits) combined with 


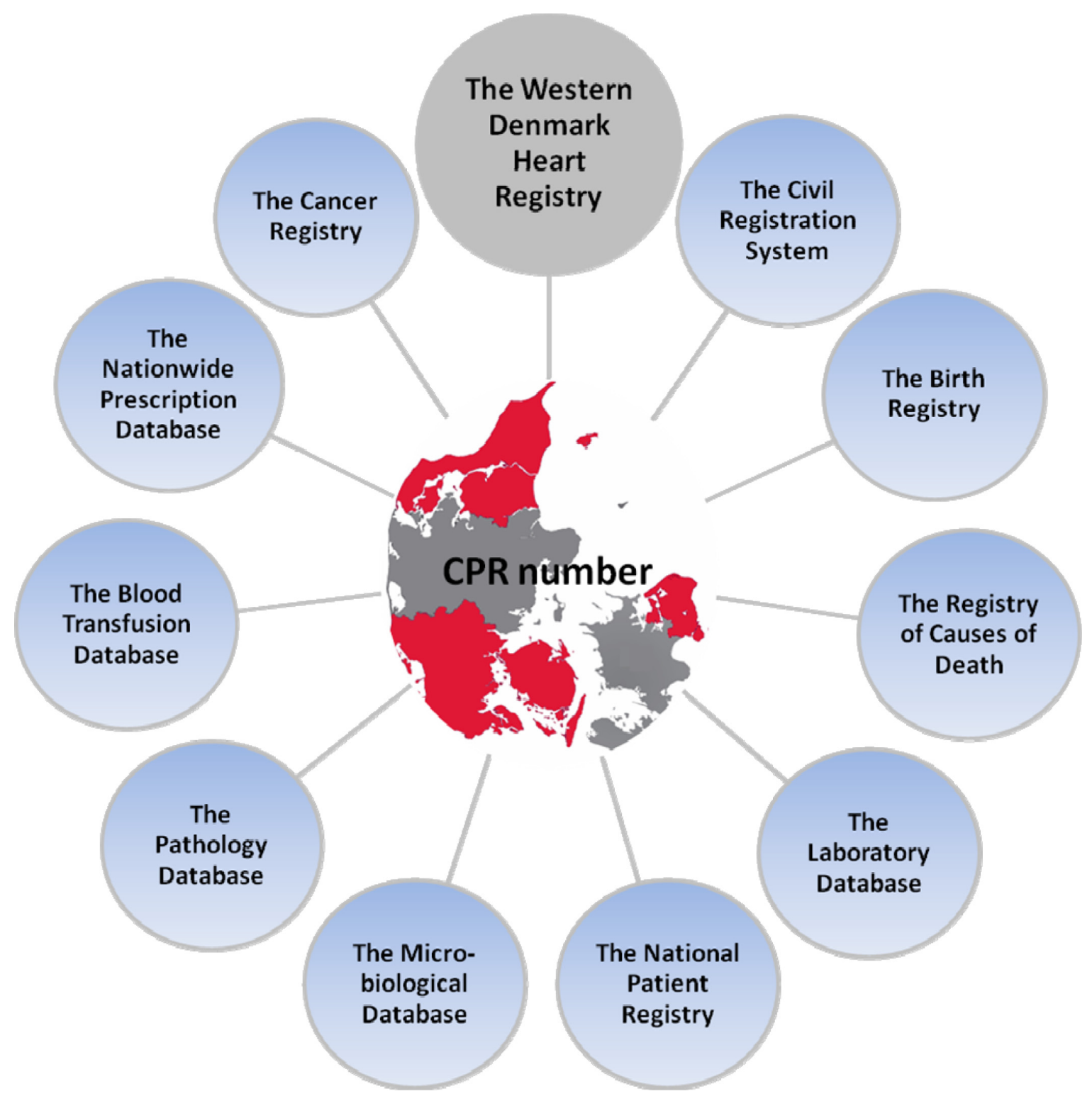

Figure 2 Record linkage potential of Danish medical databases using the central personal registry (CPR) number.

systematic validation procedures (through research projects and otherwise defined by the individual departments) and random spot checks after entry (through research projects and by the data management group). Data are entered by the physicians at the time of procedure and late procedure complications may, therefore, be incompletely recorded in the WDHR. For example, stent thrombosis may be incompletely registered unless the patient lives to receive revascularization treatment in connection with angiography. However, data linkage to national registries using the CPR numbers provides complete patient follow-up and ascertainment of late complications such as reinfarction, stroke, or cause of death.

The proportion of registrations completed (one minus the proportion of missing data) is monitored at two levels: (i) procedure registration through independent ascertainment methods, in which the number of interventions registered in the WDHR is compared with that registered in the Danish National Patient Registry. ${ }^{13}$ In 2008 it was 98\% for CAG, $98 \%$ for PCI, $97 \%$ for valve surgery, and $98 \%$ for $\mathrm{CABG} ;{ }^{10}$ (ii) variable registration through historic data methods, in which the number of registered variables for each intervention is compared with the expected number calculated from the observed number of interventions..$^{13}$ It is monitored and reported individually for the cardiac centers (Tables 1-3).

\section{Research examples}

WDHR data are well suited for studying predictors for multiple outcomes following cardiac intervention, such as 
Table I Examples of variables recorded for percutaneous coronary intervention in 2008. The proportion of completed variable registration is shown in table parentheses

\begin{tabular}{|c|c|c|c|c|c|}
\hline & \multicolumn{4}{|c|}{ Cardiac centers $^{a}$} & \multirow{2}{*}{$\begin{array}{l}\text { Total } \\
(n=5498)\end{array}$} \\
\hline & $\begin{array}{l}\text { Skejby } \\
(n=2273)\end{array}$ & $\begin{array}{l}\text { Odense } \\
(n=1659)\end{array}$ & $\begin{array}{l}\text { Aalborg } \\
(n=1 \mid 64)\end{array}$ & $\begin{array}{l}\text { Varde } \\
(n=402)\end{array}$ & \\
\hline \multicolumn{6}{|l|}{ Medical history } \\
\hline Male gender, \% & $73(100)$ & $72(100)$ & $76(100)$ & $72(100)$ & $73(100)$ \\
\hline Age, years & $65(100)$ & $64(100)$ & $64(100)$ & $64(100)$ & $65(100)$ \\
\hline Ischemic heart disease in family, \% & $49(98)$ & $45(54)$ & $43(75)$ & $63(97)$ & $48(80)$ \\
\hline Smoking (current or former), \% & $79(94)$ & $78(50)$ & $81(70)$ & $75(92)$ & $79(75)$ \\
\hline Obesity (BMI $\geq 30), \%$ & $20(96)$ & $12(45)$ & $15(65)$ & $21(82)$ & $16(73)$ \\
\hline Diabetes mellitus, $\%$ & $17(99)$ & $21(55)$ & $15(76)$ & $13(97)$ & $17(8 \mid)$ \\
\hline Lipid lowering therapy, \% & $62(98)$ & $65(55)$ & $55(75)$ & $83(97)$ & $63(80)$ \\
\hline Hypertension, \% & $51(98)$ & $51(55)$ & $53(75)$ & $59(96)$ & $52(80)$ \\
\hline Previous PCl, \% & $28(99)$ & $27(55)$ & $24(76)$ & $24(97)$ & $27(81)$ \\
\hline Previous myocardial infarction, $\%$ & $26(99)$ & $23(55)$ & $27(76)$ & $27(97)$ & $26(81)$ \\
\hline \multicolumn{6}{|l|}{ Procedure data } \\
\hline \multicolumn{6}{|l|}{$\mathrm{PCl}$ indication } \\
\hline STEMI, \% & $26(100)$ & $35(100)$ & $29(100)$ & $2(100)$ & $27(100)$ \\
\hline Non-STEMI or unstable angina, \% & $23(100)$ & $31(100)$ & $32(100)$ & $13(100)$ & $27(100)$ \\
\hline Stable angina, $\%$ & $42(100)$ & $30(100)$ & $35(100)$ & $79(100)$ & $40(100)$ \\
\hline Other, \% & $9(100)$ & $4(100)$ & $4(100)$ & $6(100)$ & $6(100)$ \\
\hline \multicolumn{6}{|l|}{ Clinical presentation ${ }^{\mathrm{b}}$} \\
\hline Acute, $\%$ & $31(100)$ & $39(100)$ & $32(100)$ & $2(100)$ & $31(100)$ \\
\hline Subacute, \% & $30(100)$ & $32(100)$ & $32(100)$ & $25(100)$ & $31(100)$ \\
\hline Elective, \% & $39(100)$ & $29(100)$ & $36(100)$ & $73(100)$ & $38(100)$ \\
\hline \multicolumn{6}{|l|}{ Target lesion revascularization } \\
\hline Stent thrombosis, \% & $2(100)$ & $2(100)$ & $2(100)$ & $0.5(100)$ & $2(100)$ \\
\hline In-stent restenosis, \% & $4(100)$ & $3(100)$ & $3(100)$ & $4(100)$ & $4(100)$ \\
\hline Non-instent restenosis, \% & $I(100)$ & $0.6(100)$ & $I(100)$ & $I(100)$ & $\mathrm{I}(100)$ \\
\hline \multicolumn{6}{|l|}{ Arterial access } \\
\hline Femoral, \% & $96(100)$ & $99(100)$ & $89(100)$ & $100(100)$ & $96(100)$ \\
\hline Radial or brachial, \% & $4(100)$ & $0.7(100)$ & II (100) & $0.2(100)$ & $4(100)$ \\
\hline Procedure time, min & $31(100)$ & $24(99)$ & $26(98)$ & $23(100)$ & $27(99)$ \\
\hline Fluoroscopy time, min & II (I00) & $10(100)$ & $9(100)$ & $8(100)$ & $10(100)$ \\
\hline X-ray dose, Gy $\mathrm{cm}^{2}$ & $88(100)$ & $28(100)$ & $62(100)$ & $58(100)$ & $62(100)$ \\
\hline Contrast volume, $\mathrm{ml}$ & $104(100)$ & $133(100)$ & $145(100)$ & $87(100)$ & $120(100)$ \\
\hline No. of treated lesions & $1.3(100)$ & $1.3(100)$ & $1.3(100)$ & $1.4(100)$ & $1.3(100)$ \\
\hline \multicolumn{6}{|l|}{ No. of treated arteries, \% } \\
\hline 0 & I (I00) & $2(100)$ & $2(100)$ & $\mathrm{I}(100)$ & $2(100)$ \\
\hline 1 & $83(100)$ & $85(100)$ & $84(100)$ & $82(100)$ & $84(100)$ \\
\hline 2 & $14(100)$ & $13(100)$ & $13(100)$ & $16(100)$ & $14(100)$ \\
\hline 3 & I (100) & $0.5(100)$ & $\mathrm{I}(100)$ & $\mathrm{I}(100)$ & $0.9(100)$ \\
\hline No. of balloons & $1.8(100)$ & $1.5(100)$ & $1.6(100)$ & $1.5(100)$ & $1.6(100)$ \\
\hline No. of stents & $1.4(100)$ & $1.3(100)$ & $1.5(100)$ & $1.3(100)$ & $1.4(100)$ \\
\hline \multicolumn{6}{|l|}{ Periprocedural antiplatelet therapy } \\
\hline Acetylsalicylic acid, \% & $98(100)$ & $98(100)$ & $91(100)$ & $99(100)$ & $97(100)$ \\
\hline Clopidogrel, \% & $92(100)$ & $97(100)$ & $85(100)$ & $97(100)$ & $92(100)$ \\
\hline Glycoprotein Ila/lllb antagonist, \% & $29(100)$ & $25(100)$ & $25(100)$ & $10(100)$ & $25(100)$ \\
\hline \multicolumn{6}{|l|}{ Lesion data } \\
\hline \multicolumn{6}{|l|}{ Lesion type, ${ }^{c} \%$} \\
\hline A & $4(95)$ & $19(94)$ & $8(9 \mathrm{l})$ & $16(95)$ & $10(94)$ \\
\hline $\mathrm{BI}$ & $20(95)$ & $27(94)$ & $24(91)$ & $26(95)$ & $23(94)$ \\
\hline B2 & $21(95)$ & $30(94)$ & $31(91)$ & $25(95)$ & $26(94)$ \\
\hline C & $55(95)$ & $24(94)$ & $37(91)$ & $33(95)$ & $40(94)$ \\
\hline Stenosis, ${ }^{d} \%$ of luminal diameter & $93(95)$ & $90(94)$ & $90(91)$ & $86(95)$ & $91(94)$ \\
\hline Lesion length, ${ }^{\mathrm{d}} \mathrm{mm}$ & $24(95)$ & $20(94)$ & $21(91)$ & $19(95)$ & $22(94)$ \\
\hline Stent length, ${ }^{\mathrm{d}}$ sum in mm & $27(85)$ & $25(97)$ & $26(87)$ & $23(97)$ & $26(86)$ \\
\hline Stent implantation $(\geq 1), \%$ & $90(95)$ & $93(94)$ & $95(91)$ & $92(95)$ & $92(94)$ \\
\hline
\end{tabular}


Table I (Continued)

\begin{tabular}{|c|c|c|c|c|c|}
\hline & \multicolumn{4}{|c|}{ Cardiac centers $^{a}$} & \multirow{2}{*}{$\begin{array}{l}\text { Total } \\
(n=5498)\end{array}$} \\
\hline & $\begin{array}{l}\text { Skejby } \\
(n=2273)\end{array}$ & $\begin{array}{l}\text { Odense } \\
(n=1659)\end{array}$ & $\begin{array}{l}\text { Aalborg } \\
(n=1 \mid 64)\end{array}$ & $\begin{array}{l}\text { Varde } \\
(n=402)\end{array}$ & \\
\hline \multicolumn{6}{|l|}{ Stent type } \\
\hline DES (with or without BMS), \% & $74(100)$ & $78(100)$ & $64(100)$ & $67(100)$ & $73(100)$ \\
\hline BMS (without DES), \% & II (100) & $8.7(100)$ & $23(100)$ & $20(100)$ & $13(100)$ \\
\hline Hospitalization time, days & $1.5(91)$ & $2.3(93)$ & $2.1(96)$ & I.I (93) & I.8 (93) \\
\hline
\end{tabular}

Notes: Values are means when \% is not indicated. a'Skejby = Aarhus University Hospital-Skejby; Odense = Odense University Hospital; Aalborg = Aarhus University Hospital-Aalborg; Varde = Varde Heart Centre. ${ }^{b}$ Acute (within hours): STEMI or cardiac arrest patients; Subacute (within days): patients with nonSTEMI, unstable angina, or crescendo angina; Elective (within weeks): patients (i) with stable angina, (ii) needing cardiac surgery, (iii) with systolic left ventricular failure, or (iv) with ventricular arrhythmias of unknown origin. 'Lesion classification with a distinction between simple BI and complex B2 lesions: $\mathrm{A}=$ non-complicated, length $<\mathrm{I} 0$ mm; $\mathrm{B}=$ irregular, length $10-20 \mathrm{~mm} ; \mathrm{C}=$ irregular, sidebranch, 90 degrees, chronic occlusion, length $>20 \mathrm{~mm} \cdot{ }^{26,27}$ dBy visual estimate.

Abbreviations: BMI, body mass index; BMS, bare-metal stent; DES, drug-eluting stent; PCl, percutaneous coronary intervention; STEMI, ST-segment elevation myocardial infarction.

patient characteristics, comorbidity, medication use, and intra-interventional differences (eg, different types of stents or anesthesia). Furthermore, the WDHR is used as a platform for randomized controlled trials with clinical driven outcome detection.

In addition to the inherent variables in the WDHR, a committee of cardiac specialists has, owing to research purposes, ${ }^{14-18}$ added detailed information on stent thrombosis and cause of death. As defined by the Academic Research Consortium, the specialist committee adjudicated the incidence of definite, probable, or possible stent thrombosis by retrieving medical records and reviewing catheterization angiograms. The committee also reviewed original paper death certificates ascertained from the National Registry of Causes of Deaths ${ }^{6}$ to classify death according to the underlying cause as cardiac or noncardiac death. Cardiac death was defined as an evident cardiac death, PCI-related death, unwitnessed death, and death from unknown causes. Thus, using these adjudicated outcomes from 12,395 patients undergoing PCI with stent implantation, Jensen et a ${ }^{14}$ concluded that the minor additional risk of stent thrombosis and myocardial infarction within 15 months after implantation of drug-eluting stents (DES) compared with bare-metal stents (BMS) was unlikely to outweigh the benefit of DES in reducing clinically necessary target lesion revascularization. ${ }^{14}$

Table 2 Examples of variables recorded for cardiac surgery in 2008. The proportion of completed variable registration is shown in table parentheses

\begin{tabular}{|c|c|c|c|c|c|}
\hline & \multicolumn{4}{|c|}{ Cardiac centers $^{a}$} & \multirow{2}{*}{$\begin{array}{l}\text { Total } \\
(n=2389)\end{array}$} \\
\hline & $\begin{array}{l}\text { Skejby } \\
(n=963)\end{array}$ & $\begin{array}{l}\text { Odense } \\
(n=527)\end{array}$ & $\begin{array}{l}\text { Aalborg } \\
(n=435)\end{array}$ & $\begin{array}{l}\text { Varde } \\
(n=464)\end{array}$ & \\
\hline \multicolumn{6}{|l|}{ Procedure data } \\
\hline EuroSCORE & $6(95)$ & $6(100)$ & $6(97)$ & $5(100)$ & $6(97)$ \\
\hline Logistic mortality, ${ }^{\mathrm{b}} \%$ & $11(95)$ & $8(100)$ & $9(97)$ & $5(100)$ & $9(97)$ \\
\hline Previous $\mathrm{PCl}, \%$ & $12(85)$ & $18(100)$ & $14(84)$ & $9(100)$ & $13(91)$ \\
\hline \multicolumn{6}{|l|}{ Operation, \% } \\
\hline CABG only & $4 I(100)$ & $49(100)$ & $57(100)$ & $54(100)$ & $48(100)$ \\
\hline Valve surgery $(0 \geq C A B G)$ & $39(100)$ & $31(100)$ & $28(100)$ & $40(100)$ & $35(100)$ \\
\hline Other & $21(100)$ & $20(100)$ & $15(100)$ & $6(100)$ & $17(100)$ \\
\hline Time to procedure, days & $54(94)$ & $30(99)$ & $30(97)$ & $19(100)$ & $37(97)$ \\
\hline Acute surgery, $\%$ & $9(95)$ & $10(100)$ & $8(97)$ & $I(100)$ & $7(97)$ \\
\hline CABG On-Off-Pump, \% & $84(82)$ & $61(100)$ & $87(82)$ & $98(100)$ & $82(90)$ \\
\hline ECC time, $\min$ & $98(99)$ & $125(100)$ & $110(100)$ & $60(95)$ & $97(98)$ \\
\hline Aortic clamp duration, min & $60(98)$ & $83(98)$ & $68(99)$ & $38(97)$ & $61(98)$ \\
\hline Hospitalization time, days & $14(88)$ & $11(99)$ & $10(83)$ & 7 (99) & II (92) \\
\hline
\end{tabular}


Table 3 Performance indicators in 2008. The proportion of completed variable registration is shown in table parentheses

\begin{tabular}{|c|c|c|c|c|c|}
\hline \multirow{2}{*}{$\begin{array}{l}\text { Performance indicators } \\
\left.\text { (standards }{ }^{b}\right)\end{array}$} & \multicolumn{4}{|c|}{ Cardiac centers ${ }^{\mathrm{a}}$} & \multirow[t]{2}{*}{ Total } \\
\hline & Skejby & Odense & Aalborg & Varde & \\
\hline \multicolumn{6}{|l|}{ PCl } \\
\hline Contrast fluid reaction ${ }^{c}(<\mathrm{I}), \%$ & $0.1(100)$ & $0.0(100)$ & $0.1(100)$ & $0.2(100)$ & $0.1(100)$ \\
\hline $\operatorname{Arrhythmiac}^{c}(<\mathrm{I}), \%$ & $0.4(100)$ & I.I (100) & $0.9(100)$ & $0.2(100)$ & $0.7(100)$ \\
\hline Arterial puncture bleeding $(<3), \%$ & $0.7(92)$ & $3.5(94)$ & $0.9(100)$ & $0.3(93)$ & I.5 (94) \\
\hline Acute $\mathrm{CABG}^{\mathrm{c}}(<0.5), \%$ & $0.1(100)$ & $0.1(100)$ & $0.2(100)$ & $0.0(100)$ & $0.1(100)$ \\
\hline 30-day mortality $(<5), \%$ & $2.6(99)$ & $3.5(99)$ & $3.6(99)$ & $0.3(96)$ & $2.9(99)$ \\
\hline \multicolumn{6}{|l|}{ Cardiac surgery } \\
\hline Central nervous lesion ${ }^{\mathrm{d}}(<5), \%$ & $\mathrm{I} .0(97)$ & $\mathrm{I} .0(100)$ & $2.6(87)$ & $0.4(99)$ & I.I (96) \\
\hline Acute myocardial infarction ${ }^{d}(<5), \%$ & $2.7(85)$ & $3.6(99)$ & I.I (87) & $6.6(98)$ & $3.5(91)$ \\
\hline Sternum infection ${ }^{d}(<3), \%$ & $1.9(97)$ & $0.4(100)$ & $0.5(87)$ & $0.2(99)$ & $1.0(96)$ \\
\hline Reintervention due to bleeding $(<10)$, \% & $7.3(97)$ & $6.1(100)$ & $4.7(88)$ & $5.5(99)$ & $6.2(96)$ \\
\hline Reintervention within 6 months $(<10)$, \% & $5.2(100)$ & $3.6(100)$ & $6.7(100)$ & $1.9(100)$ & $4.5(100)$ \\
\hline 30-day mortality $(<5), \%$ & $2.8(99)$ & $5.9(100)$ & $3.7(100)$ & I.I (97) & $3.3(99)$ \\
\hline
\end{tabular}

Notes: a Cardiac centers: Skejby = Aarhus University Hospital-Skejby; Odense = Odense University Hospital; Aalborg = Aarhus University Hospital-Aalborg; Varde = Varde Heart Centre. ${ }^{\mathrm{b}}$ Treatment standards set by the Danish Heart Registry; ' $D$ uring procedure; dDuring hospitalization.

Abbreviations: $\mathrm{CABG}$, coronary artery bypass grafting; $\mathrm{PCl}$, percutaneous coronary intervention.

The reduction in target lesion revascularization was also confirmed for ST-segment elevation myocardial infarction patients who were treated with primary $\mathrm{PCI}^{19}$ and for diabetic patients. ${ }^{20}$ Furthermore, comparing effectiveness of two types of DES - sirolimus-eluting stents (SES) and paclitaxel-eluting stents (PES) - Maeng et $\mathrm{al}^{17}$ showed that PES increased the risk of target lesion revascularization by $43 \%$ compared with SES. ${ }^{17}$ In addition, Kaltoft et $\mathrm{a}^{16}$ concluded that within two years of follow-up, PES increased the risk of stent thrombosis, myocardial infarction, and 1-year mortality compared with BMS and SES. ${ }^{16}$ Cardiovascular outcomes have also been examined for other high risk patients with eg, spontaneous coronary artery dissection, ${ }^{21}$ or unprotected left main coronary artery stenosis treated with PCI. ${ }^{15}$

Obtaining information on all prescription medication through record linkage to the Nationwide Prescription Database makes the WDHR a valuable source for pharmacoepidemiological cardiovascular research. Use of nonselective NSAIDs and COX-2-selective enzyme inhibitors has been reported to increase cardiovascular risks in patients with coronary artery disease..$^{22,23}$ Schmidt et $a{ }^{18}$ examined whether this risk also related to patients undergoing coronary stent implantation, and found that overall there was no evidence to support such an association. ${ }^{18}$

In patients undergoing cardiac surgery, Jakobsen et $\mathrm{a}^{24}$ investigated the cardioprotective effect of sevoflurane versus propofol anesthesia and found that sevoflurane seemed superior to propofol in patients with little or no ischemic heart disease, whereas propofol seemed superior in patients with severe ischemia, cardiovascular instability, or in acute or urgent surgery. ${ }^{24}$ In another study on drug effectiveness and safety during cardiac surgery, aprotinin treatment was found to increase the use of plasma and platelet transfusion and the risk for postoperative dialysis, but not other adverse outcomes, including short-term mortality. ${ }^{25}$

\section{Conclusions}

The WDHR is a valuable tool for clinical epidemiological research because it provides ongoing longitudinal registration of detailed patient and procedure data, which allows for research within invasive cardiology, cardiac surgery, anesthesia, and pharmacoepidemiology. The Danish national health care system enables this research because it allows complete follow-up for medical events after cardiac intervention by linkage with multiple medical databases.

\section{Disclosures}

The authors report no conflicts of interest in this work.

\section{More information}

The WDHR is administered according to Danish law. The data may be used in international collaborations at the discretion of the board and the participating cardiac centers. Additional information about the WDHR can be obtained through the corresponding author. Potential collaborators are invited to contact the board through Department of Cardiology, Aarhus University Hospital-Skejby. 


\section{References}

1. The Danish National Board of Health. Future need for revascularization treatment of ischemic heart disease - including PCI treatment (Heart Plan 2003) 2003.

2. Abildstrøm SZ, Kruse M, Rasmussen S, et al. The Danish Heart Registry-a clinical database. Ugeskr laeger. 2008;170(7):532-536.

3. www.hjerteregister.dk

4. Frank L. Epidemiology: when an entire country is a cohort. Science. 2000;287(5462):2398-2399.

5. Pedersen CB, Gøtzsche H, Møller JO, Mortensen PB. The Danish Civil Registration System. A cohort of eight million persons. Dan Med Bull. 2006;53(4):441-449.

6. Juel K, Helweg-Larsen K. The Danish registers of causes of death. Dan Med Bull. 1999;46(4):354-357.

7. Andersen TF, Madsen M, Jorgensen J, Mellemkjaer L, Olsen JH. The Danish National Hospital Register. A valuable source of data for modern health sciences. Dan Med Bull. 1999;46(3):263-268.

8. Sørensen R, Hansen ML, Abildstrom SZ, et al. Risk of bleeding in patients with acute myocardial infarction treated with different combinations of aspirin, clopidogrel, and vitamin $\mathrm{K}$ antagonists in Denmark: a retrospective analysis of nationwide registry data. Lancet. 2009;374(9706):1967-1974.

9. Christiansen JU, Maruard CD, Nielsen HC. LABKA. A real-time computer system for the clinical laboratory. Scand J Clin Lab Invest Suppl. 1989;194:57-61.

10. The board of Western Denmak Heart Registry. Western Denmark Heart Registry. Annual Report 2008 (Data from 2007 and 2008) 2009.

11. Brook RH, McGlynn EA, Cleary PD. Quality of health care. Part 2: measuring quality of care. N Eng J Med. 1996;335(13):966-970.

12. Mainz J. Defining and classifying clinical indicators for quality improvement. Int J Qual Health Care. 2003;15(6):523-530.

13. Sorensen HT, Sabroe S, Olsen J. A framework for evaluation of secondary data sources for epidemiological research. Int J Epidemiol. 1996;25(2):435-442.

14. Jensen LO, Maeng M, Kaltoft A, et al. Stent thrombosis, myocardial infarction, and death after drug-eluting and bare-metal stent coronary interventions. J Am Coll Cardiol. 2007;50(5):463-470.

15. Jensen LO, Kaltoft A, Thayssen P, et al. Outcome in high risk patients with unprotected left main coronary artery stenosis treated with percutaneous coronary intervention. Catheter Cardiovasc Interv. 2009;75(1):101-108.

16. Kaltoft A, Jensen LO, Maeng M, et al. 2-year clinical outcomes after implantation of sirolimus-eluting, paclitaxel-eluting, and bare-metal coronary stents: results from the WDHR (Western Denmark Heart Registry). J Am Coll Cardiol. 2009;53(8):658-664.

17. Maeng M, Jensen LO, Rasmussen K, et al. Target lesion revascularisation in patients treated with a sirolimus-eluting or paclitaxel-eluting stent. Heart. 2007;93(6):694-697.
18. Schmidt M, Maeng M, Pedersen L, Lassen JF, Nielsen TT, Sørensen HT. Do selective cyclooxygenase-2 inhibitors and nonselective nonsteroidal antiinflammatory drugs increase the risk of cardiovascular events and death after intracoronary stenting? [Abstract]. Pharmacoepidemiol Drug Saf. 2009;18 Suppl 1:113.

19. Jensen LO, Maeng M, Thayssen $P$, et al. Clinical outcome after primary percutaneous coronary intervention with drug-eluting and bare metal stents in patients with ST-segment elevation myocardial infarction. Circulation Cardiovasc Interv. 2008;1(3):176-184.

20. Maeng M, Jensen LO, Kaltoft A, et al. Comparison of stent thrombosis, myocardial infarction, and mortality following drug-eluting versus bare-metal stent coronary intervention in patients with diabetes mellitus. Am J Cardiol. 2008;102(2):165-172.

21. Mortensen KH, Thuesen L, Kristensen IB, Christiansen EH. Spontaneous coronary artery dissection: a Western Denmark Heart Registry study. Catheter Cardiovasc Interv. 2009;74(5):710-717.

22. Gislason GH, Jacobsen S, Rasmussen JN, et al. Risk of death or reinfarction associated with the use of selective cyclooxygenase-2 inhibitors and nonselective nonsteroidal antiinflammatory drugs after acute myocardial infarction. Circulation. 2006;113(25):2906-2913.

23. Ray WA, Varas-Lorenzo C, Chung CP, et al. Cardiovascular risks of nonsteroidal antiinflammatory drugs in patients after hospitalization for serious coronary heart disease. Circulation: Cardiovascular Quality and Outcomes. 2009;2(3):155-163.

24. Jakobsen CJ, Berg H, Hindsholm KB, Faddy N, Sloth E. The influence of propofol versus sevoflurane anesthesia on outcome in 10,535 cardiac surgical procedures. J Cardiothorac Vasc Anesth. 2007;21(5):664-671.

25. Jakobsen CJ, Søndergaard F, Hjortdal VE, Johnsen SP. Use of aprotinin in cardiac surgery: effectiveness and safety in a population-based study. Eur J Cardiothorac Surg. 2009;36(5):863-868.

26. Ryan TJ, Faxon DP, Gunnar RM, et al. Guidelines for percutaneous transluminal coronary angioplasty. A report of the American College of Cardiology/American Heart Association Task Force on Assessment of Diagnostic and Therapeutic Cardiovascular Procedures (Subcommittee on Percutaneous Transluminal Coronary Angioplasty). Circulation. 1988;78(2):486-502.

27. Ellis SG, Vandormael MG, Cowley MJ, et al. Coronary morphologic and clinical determinants of procedural outcome with angioplasty for multivessel coronary disease. Implications for patient selection. Multivessel Angioplasty Prognosis Study Group. Circulation. 1990; 82(4):1193-1202.

28. Nashef SA, Roques F, Hammill BG, et al. Validation of european system for cardiac operative risk evaluation (EuroSCORE) in North American cardiac surgery. Eur J Cardiothorac Surg. 2002;22(1):101-105.
Clinical Epidemiology

\section{Publish your work in this journal}

Clinical Epidemiology is an international, peer-reviewed, open access journal focusing on disease and drug epidemiology, identification of risk factors and screening procedures to develop optimal preventative initiatives and programs. Specific topics include: diagnosis, prognosis, treatment, screening, prevention, risk factor modification, systematic

Submit your manuscript here: http://www.dovepress.com/clinical-epidemiology-journal

\section{Dovepress}

reviews, risk \& safety of medical interventions, epidemiology \& biostatical methods, evaluation of guidelines, translational medicine, health policies \& economic evaluations. The manuscript management system is completely online and includes a very quick and fair peer-review system, which is all easy to use. 